\title{
INTERNET OF THINGS FOR FARMERS: EDUCATIONAL ISSUES
}

\author{
Boris Medvedev, Sergey Molodyakov \\ Peter the Great Saint-Petersburg Polytechnic University, Russia \\ medvedev@ics2.ecd.spbstu.ru, samolodyakov@mail.ru
}

\begin{abstract}
Efforts of many countries aimed at the development of the Internet of Things in agriculture can give little effect because of limited knowledge and practical skills, which are necessary for farmers to make decisions on investment into the technologies of Smart agriculture. Development of IoT educational programs is faced with challenging issues. Ageing: only $6 \%$ of farmers in Europe are younger than 35 years. Distance: the vast majority of farmers have no opportunity to attend courses at the universities within weeks. Complexity: IoT in agriculture represents the multidisciplinary field in education including earth sciences, measurement and control technologies, telecommunication systems and data processing. Financing: the "must have" practical skills will help IoT users break a psychological barrier, however, creation of training grounds can involve big financial costs. The answer to these contradictory requirements is curriculum development based on the analysis of IoT business models and specialist models. The result of the work is the proposed set of problem oriented and audience oriented courses in the form of distance learning. Each course with duration of 20 hours contains lectures, practical training and a test. Lectures are devoted to relevant problems of IoT. For the practical training each trainee uses his/her own smartphone to convert it into the IoT device. With the help of step-by-step instruction a user can register his IoT device in the cloud service and switch on transmission of the smartphone movement or light sensor data for processing in a cloud. Data processing results can be viewed as feedback to smartphone and via web application. Successful implementation of the course tasks is confirmed by the graduation certificate. Regional adaptation and government support of farmers and training organizers are necessary for widespread introduction of courses.
\end{abstract}

Keywords: IoT, smart agriculture, distance learning.

\section{Introduction}

The growth of global population demands for more food produced by agriculture. At the same time, such challenges as the climate change and environmental impact, resulting from industry and intensive farming practices, have to be met. Smart farming (SF) based on the Internet of Things (IoT) technologies will enable farmers to reduce losses and enhance productivity. Russian Federation, European Union and many other countries worldwide initiate extensive programs aimed at the development of IoT in agriculture [1;2]. These efforts will give little effect, if farmers will possess insufficient knowledge level and practical skills, which are necessary for them to make decisions on investment into the technologies of Smart agriculture. The gap between the interests and expectations of the research and the farmer communities led to a low adoption of SF technologies: no more than $24 \%$ of farmers use some kind of SF in Europe [2].

Persons interested in IoT education can be divided into 3 groups. The first group includes higher school students, who are studying agriculture academic programs. Most universities have a range of disciplines that deal with SF issues. As an example, the University of Queensland (Australia) developed the Technology Enhanced Learning Project that is based on the IoT system [3]. The second group consists of students of the Computer Science and Electrical Engineering departments and IT specialists, who are interested in gaining additional knowledge to implement projects in the newly emerged and large SF market segment. The third group consists of farmers of small and medium-sized agricultural enterprises, for whom the application of SF technologies is a matter of survival in the near future, as it is becoming more difficult for them to compete with large farms that have the opportunity to hire IT specialists.

The aim of the research is development of the curriculum with a set of theory and practice training in the field of IoT in smart farming that is provided for farmers and IT specialists on demand.

The main problem of the research is an obtainment of balance between the large amount of knowledge in theory and practice training in IoT for smart agriculture and limited time and technique resources possessed by trainees, who are not students of agriculture academic programs.

Development of IoT educational programs for farmers and IT specialists is faced with challenging issues. Curriculum designed for students of the first group is difficult to use for persons in groups 2 and 3. Consider the fact that only $6 \%$ of farmers in Europe are younger than 35 years and $56 \%$ are 
older than 55 [4]. The pedagogical methods used to train young people need to be adapted for an older audience. Basic university courses are developed for teaching students during several years, but the vast majority of farmers have no opportunity to attend courses at the universities within such long period.

IoT in agriculture represents the multidisciplinary field in education including earth sciences, measurement and control technologies, telecommunication systems and data processing. Development of the curriculum demands joint efforts of teachers in different specialties. Smart farming is a capitalintensive and hi-tech system of growing food with application of modern information and communication technologies into agriculture. The core of IoT is software data processing embedded in IoT devices, gateways, cloud services and user applications [5]. At the same time, software is the least studied discipline for farmers.

The answer to these contradictory requirements can be a set of problem oriented and audience oriented courses in the form of distance learning. Most of the existing distance learning courses contain lectures in the form of video on demand or webinar, and little attention is paid to practical exercises [6; 7]. New knowledge degrades rapidly without practical skills. However, creation of full scale training grounds can involve large financial costs [3].

The article is devoted to the development of an IoT distance learning course with practical training that requires little or no additional financial expenses. For practical training each trainee uses his/her own smartphone to convert it into the IoT device.

\section{Materials and methods}

The curriculum development methodology is based on the analysis of IoT business models and specialist models. Business models highlight a variety of the IoT ecosystem players relationships in real deployments and can be used for target audience definition. The specialist model specifies a set of competencies in the area of interest, which are necessary for successful implementation of functional duties.

IoT business models can be found in Appendix I of the International Telecommunication Union Recommendation ITU-T Y.2060 "Overview of the Internet of things" [8]. Models include:

- The device provider, which is responsible for devices providing data and content to the network provider and application provider according to the service logic.

- The network provider, which is offering IoT capabilities, including network capabilities and resource exposure to other providers.

- The platform provider, which provides data storage, data processing and device management.

- The application provider utilizes capabilities or resources provided by the network provider, device provider and platform provider in order to provide IoT applications to application customers.

- The application customer is the user of the IoT application provided by the application provider.

ITU-T Y.2060 model 5 is used in our investigation. The model includes 3 players and the application customer: player A (cellular network operator as an example) only operates the network, player B (IBM Watson IoT Platform as an example) operates the platform, and player C (software developer) acts as the device provider and application provider and provides the devices functionality by embedded software development and applications to the application customer (farmer).

Software developer and farmer demonstrate close relationships in the model from the IoT device side and application side. These players should have common understanding in the fields of smart farming and software as the software developer and advanced end-user. Thus, these players form a common target audience for training. Curriculum should contain a generic part devoted to the basics of smart farming (including data processing and system control) and an extended part devoted to software development technologies for IT specialists.

A set of competences as curriculum targets can be derived from a model of specialist. The most complex set of IoT competences should demonstrate the IoT devices embedded software developer [5]. On average, each employee performs more than 6 functional duties including system design, 
development of firmware/software for embedded systems, architecture selection and specification, hardware/software co-design and integration, project management. The embedded software developer must have knowledge and competencies in complementary areas: circuit technology, tools and methods for analog and digital devices design, software testing and verification, computer networks and smart farming as the application area. A farmer should be familiar with smart farming technologies based on software data processing and control in order to be an advanced end-user of such systems and to be able to make corrections if necessary. Due to the fact that the IoT embedded system project time is usually short (significant part of the projects has duration of 6 to 12 months) and almost half of the projects are new [9], educational organizations should respond to the learning needs with short-term courses on demand.

The advantage of distance learning is the opportunity to get education for goal-oriented people, who cannot study full-time at the university, or those, who wish to improve their skills.

There are three levels of distance learning organization [10]:

1. Developer level - a teacher of distance courses elaborates methods of teaching, testing methods, student motivation [11;12].

2. Administration level - disciplines and curriculum development in the framework of the institute (faculty), courses certification, organization and support of an educational portal, educational services marketing.

3. Initiation and policies level - application of distance learning (educational department of the university, the ministry).

The best approach for the "IoT in agriculture" curriculum development is a set of short-term distance learning courses, forming the basic and optional parts of the discipline. Basic courses should contain generic lectures and starting level practical training, while optional courses should be devoted to specific issues of smart agriculture. Combination of basic and several optional courses is selected by a student.

Distance learning is a complex process of learning and special means are required to maintain the motivation to study. Such means may include: sending letters to inactive participants; taking into account students suggestions; organization of work in teams; regular summarizing of individual and team work of students. Learning motivation can be increased by the graduation certificate issued after successful completion of the course. The use of new information technologies attracts young teachers; open access and competition between similar courses on open education platforms make it necessary to update and improve the course. Advertising of the university by placing distance learning courses on open portals is also an important motivation for using distance learning. Distance courses attract a new contingent to universities. It is worth mentioning that distance learning technologies allow to simplify the teachers work during practical training and tests, although courses development and support requires a lot of extra effort.

\section{Results and discussion}

The following key features of smart agriculture define the set of topics for distance learning courses:

1. IoT-based smart agriculture sensor networks collect, record, analyze and visualize the data. The farmer can monitor the current state in the business and make the right decisions.

2. Gathered and analyzed in cloud services big data give an opportunity to the farmer to foresee the amount of products worked out in his farm and in the region, thus providing modernization of product distribution and minimizing the risks of financial losses.

3. Smart agriculture technologies automate various business processes and make them more efficient. Water flow control and water quality monitoring save water and provide improvement of water quality. Accurate fertilization saves fertilizer. Remote control of farm machinery provides operation monitoring and diagnosis of machinery breakdown. Engineering system control of buildings provides savings in electricity, water and heat energy consumption.

4. Smart agriculture allows improving the final product quality. Traceability system of the farm production supply chain shortens the delivery time. Disease and pest monitoring, and 
identification of individual animals allow healthy cultivation; the issues are typically detected and mitigated beforehand.

The analysis has shown that many different smart farming topics can be combined into the following problem oriented distance learning courses.

- "Smart farming technologies" includes an overview of IoT applications in agriculture.

- "IoT hardware platforms and telecommunications" contains the basics of sensors, actuators, micro-controllers and telecommunication equipment.

- "IoT Software" includes the basics of IoT devices embedded software, data processing software (fog computing, cloud services), as well as the user applications software.

- "IoT business models" highlights the IoT ecosystem, which consists of many stakeholders, and business models of IoT introduction.

- "IoT standardization" contains the basics of IoT interfaces and protocols standardization, connectivity and inter-operability of devices and processing centers, thus reducing the cost of devices and system maintenance.

Interactive forms of education are also used for practical training in distance learning courses, usually using simulators, or, in rare cases, expensive equipment that provides access to control functions through a web interface. The use of simple simulators in practical exercises related to the study of the Internet of Things does not ensure the proper degree of involvement in the process due to the psychological characteristics of students' perception. A higher level of communication, visualization and practical orientation is required.

Two practical training scenarios have been developed. The first scenario is designed for farmers and can also be used to train specialists in various fields, such as construction, housing management, etc., who need knowledge and practical skills in using the Internet of Things technologies. The second scenario is intended for students and trainees of advanced training courses in the specialty "Software Engineering". Both scenarios involve the use of the student's smartphone as the IoT device, processing the device's messages in the cloud service and implementing feedback: transferring the processing results to the smartphone in the form of text messages and commands. Both scenarios contain the following sequence of steps: downloading an application to a smartphone, registering a user, launching demo examples and executing them, sending the results of execution to a teacher.

A distinctive feature of the second scenario is the development of IoT application by students. An example of such an application is the use of a built-in light sensor in a smartphone to create a simplified version of a weather station. Such a device sends information about illumination and location to the cloud service, in the cloud service these data are processed together with the weather forecast, and then a text message is generated to the user.

To accomplish practical tasks, a step-by-step instruction was developed, which contains recommendations for each item of the task and a description of the ways to solve problems, including finding answers to frequently asked questions and interactive communication with the teacher. In the first scenario, a job completion text message containing a unique code generated in the cloud service based on the user ID and the date of execution is used to monitor the execution of the task. To control the fulfillment of the task, the second scenario envisages formation of a text report containing the technologies used, description of interaction classes, screenshots of the created program and the program code itself.

\section{Conclusions}

We propose the set of problem oriented and audience oriented IoT courses in the form of distance learning. Each course with duration of 20 hours contains lectures, practical training and a test. Lectures are devoted to relevant problems of IoT. For the practical training each trainee uses his/her own smart-phone to convert it into the IoT device. With the help of step-by-step instruction a user can register his IoT device in the cloud service and switch on transmission of the smart-phone movement or light sensor data for processing in a cloud. Data processing results can be viewed as feedback to the smart-phone and via web application. Successful implementation of the course tasks is confirmed by the graduation certificate. 
Regional adaptation and government support of farmers and training organizers are necessary for widespread introduction of the courses.

Investigation of shortcomings, failures and successes of the courses quality from trainers' and trainees' side is a future task that will be implemented by the course feedback analysis.

\section{References}

[1] Концепция «Научно-технологического развития цифрового сельского хозяйства «Цифровое сельское хозяйство» (The concept of "Scientific and technological development of digital agriculture "Digital Agriculture") 2018. 50 p. (In Russian) [online] [27.03.2019]. Available at: http://www.viapi.ru/download/2018/Цифровое сельское хозяйство.pdf.

[2] Smart Farming Thematic Network. Thematic Network Newsletter, January, 2017, [online] [27.03.2019]. Available at: https://ec.europa.eu/eip/agriculture/sites/agrieip/files/field_core_attachments/nw_smartakis_10012017_en.pdf.

[3] Bryceson K.P., Borrero A.N., Gunasekera K. Internet Of Things (IoT) - Smart Agriculture Education At The University Of Queensland. Proceedings of EDULEARN16 Conference, July 46, 2016, Barcelona, Spain, pp. 8036-8044.

[4] FARMING 4.0: The Future Of Agriculture? [online] [27.03.2019]. Available at: https://euagenda.eu/upload/publications/untitled-62960-ea.pdf.

[5] Medvedev B.M., Molodyakov S.A., Ustinov S.M., Fyodorov S.A. Embedded systems software: Trends in industry and education. Proceedings of International Symposium on Consumer Technologies, ISCT 2018; May 11-12, 2018, Petersburg; Russian Federation, pp. 66-69.

[6] Industrial Impact of IoT: Agriculture. University of New South Wales in Sydney, Australia. [online] [27.03.2019]. Available at: http://agthentic.com/courses/.

[7] Internet of Things (IoT) for Agriculture Webinar Series. Open Learning Campus, World Bank Group. [online] [27.03.2019]. Available at: https://olc.worldbank.org/content/internet-things-iotagriculture-webinar-series.

[8] Recommendation ITU-T Y.2060 “Overview of the Internet of things”. ITU, 2013.

[9] Embedded Markets Study. Integrating IoT and Advanced Technology Designs, Application Development \& Processing Environments. April 2017. [online] [25.04.2019]. Available at: https://m.eet.com/media/1246048/2017-embedded-market-study.pdf.

[10] Молодяков С.А., Сараджишвили С.Э. Применение дистанционных технологий для расширения возможностей образовательной деятельности в институте (The use of distance technologies for the expansion of educational activities at the institute). St. Petersburg Polytechnical University Journal. Humanities and social sciences: Научно-технические ведомости СПбГПУ. Гуманитарные и общественные науки. 2017, Т. 8. o 4. pp. 127-136. (In Russian).

[11] The Theory and Practice of Online Learning. Anderson T. Athabasca University, 2008. 472 p.

[12] Kentnor H. Distance Education and the Evolution of Online Learning in the United States. Curriculum and Teaching Dialogue, vol. 17, 2015. 